\title{
THE INVESTIGATION OF CONDITIONS OF API FROM GROUP OF CALCIUM CHANNEL BLOCKERS EXTRACTION BY ORGANIC SOLVENTS BY USING HIGH-PERFORMANCE LIQUID CHROMATOGRAPHY AS ASSAY METHOD
}

\author{
OLGYA POLYAUK, LILIYA LOGOYDA* \\ Department of Pharmaceutical Chemistry, I. Ya. Horbachevsky Ternopil State Medical University, Ukraine. Email: logojda@tdmu.edu.ua \\ Received: 11 June 2017, Revised and Accepted: 12 July 2017
}

\section{ABSTRACT}

Objective: The objective of this research was to select the optimal conditions for extraction of API from calcium channel blockers (amlodipine, nifedipine, and verapamil) by organic solvents from water solutions in dependence on $\mathrm{pH}$ solutions.

Methods: The chromatographic analysis of amlodipine, nifedipine, and verapamil performed on liquid chromatography Agilent 1200.

Results: The quantitative determination of API from calcium channel blockers (amlodipine, nifedipine, and verapamil) by high-performance liquid chromatography - method has been conducted. As a result of studies, we have found that the optimal extragent is chloroform, which is extracted at pH 7-82.1\% of amlodipine, $\mathrm{pH}$ 5-76.2\% of nifedipine, and $\mathrm{pH}$ 8-95.1\% verapamil hydrochloride. API from calcium channel blockers (amlodipine, nifedipine, and verapamil) least extracted with hexane at $\mathrm{pH}$ 2.0, so these conditions may be cleaned extract from coextractives impurities.

Conclusion: The results obtained in this research work clearly indicated that the extraction of API from calcium channel blockers (amlodipine, nifedipine, and verapamil) by organic solvents from water solutions in dependence on $\mathrm{pH}$ solutions has been conducted.

Keywords: Extraction, Organic solvents, Amlodipine, Nifedipine, Verapamil, High-performance liquid chromatography.

(C) 2017 The Authors. Published by Innovare Academic Sciences Pvt Ltd. This is an open access article under the CC BY license (http://creativecommons. org/licenses/by/4. 0/) DOI: http://dx.doi.org/10.22159/ajpcr.2017.v10i10.20506

\section{INTRODUCTION}

Calcium channel blockers, calcium channel antagonists, or calcium antagonists are several medications that disrupt the movement of calcium $\left(\mathrm{Ca}^{2+}\right)$. Calcium channel blockers are also frequently used to alter heart rate, to prevent cerebral vasospasm, and to reduce chest pain caused by angina pectoris. Calcium channel blockers are used as antihypertensive drugs, i.e., as medications to decrease blood pressure in patients with hypertension [1]. Modern methods of isolating drugs from biological material based on the individual physic-chemical properties of the compounds, so the choice of optimal conditions for isolation from biological objects, cleaning extracts of impurities are a pressing issue for improving existing and developing new methods of analytical and bioanalytical analysis.

Our aim was to select the optimal conditions for extraction of API from calcium channel blockers (amlodipine, nifedipine, and verapamil) by organic solvents from water solutions in dependence on $\mathrm{pH}$ solutions.

\section{METHODS}

The main quantitative measure of extraction is the degree of extraction (R) - the ratio of the extracted material to the total (initial) of the substance in the aqueous solution. Amount of API was determined experimentally using high-performance liquid chromatography (HPLC) method [2-4]. Choosing organic solvents due to their use in the pharmaceutical analysis of drugs for the isolation and purification of extracts from biological material - hexane, chloroform, methylenchloride.

To investigate the degree of extraction of API from calcium channel blockers (amlodipine, nifedipine, verapamil) from aqueous solutions of organic solvents used standard solutions, which was prepared with concentrations: Standard solution concentration of amlodipine besylate is $100 \mu \mathrm{g} / \mathrm{ml}$ in $0.01 \mathrm{~mol} / \mathrm{l}$ hydrochloric acid, standard solution concentration of nifedipine is $40 \mu \mathrm{g} / \mathrm{ml}$ in $0.01 \mathrm{~mol} / \mathrm{l}$ hydrochloric acid, and standard solution concentration of verapamil is $40 \mu \mathrm{g} / \mathrm{ml}$ in $0.01 \mathrm{~mol} / \mathrm{l}$ hydrochloric acid. Assay performed using previously developed conditions [5-8]: Research of API from calcium channel blockers (amlodipine, nifedipine, and verapamil) extraction conditions with aqueous solutions of organic solvents was performed by the following procedure: The number of separating funnels made in $8.00 \mathrm{ml}$ of buffer solutions and $2.00 \mathrm{ml}$ of standard solution of API from calcium channel blockers (amlodipine, nifedipine, and verapamil); to the resulting mixture was added $10.00 \mathrm{ml}$ appropriate organic solvent. Mixtures shaken in separating funnel for 5 minutes and left for 10 minutes to separate the layers.

Collected organic layers in a beaker and evaporated in a water bath to dryness, which was dissolved in $5 \mathrm{ml}$ of ethanol, quantitatively transferred to a volumetric flask and $10.0 \mathrm{~mL}$ of solvent was adjusted to the mark. Amount of API was determined experimentally using HPLC method. The experiment was performed three times for each $\mathrm{pH}$ studied for organic solvents. Need $\mathrm{pH}$ created using universal buffer BritonaRobinson ( $\mathrm{pH}=1.8$ ) and $0.2 \mathrm{M}$ sodium hydroxide from 2.0 to 12.0 . The pH installed in the application of pH meter - pH 150 MI (2011, Russia).

The chromatographic analysis of amlodipine performed on liquid chromatography Agilent 1200.

Chromatography was performed on liquid chromatography with spectrophotometric detector under the following conditions:

- Ascentis C18 column size $4.6 \times 150 \mathrm{~mm}$ with a particle size of 5 microns;

- Mobile phase:acetonitrile R - $0.1 \%$ solution of trifluoroacetic acid R (40:60);

- The rate of mobile phase: $1.0 \mathrm{ml} /$ minutes;

- Column temperature: $30^{\circ} \mathrm{C}$;

- Detection wavelength: $237 \mathrm{~nm}$. 
The chromatographic analysis of nifedipine performed on liquid chromatography Agilent 1200.

Chromatography was performed on liquid chromatography with spectrophotometric detector under the following conditions:

- Ascentis express-C18 $(4.6 \times 150 \mathrm{~mm}, 5 \mu)$ column size with a particle size of 5 microns;

- Mobile phase: methanol R - $0.1 \%$ solution of trifluoroacetic acid R (55:45);

- The rate of mobile phase: $1.5 \mathrm{ml} /$ minutes;

- Column temperature: $35^{\circ} \mathrm{C}$;

- Detection wavelength: $265 \mathrm{~nm}$.

The chromatographic analysis of verapamil hydrochloride performed on liquid chromatograph Agilent 1200.

Chromatography was performed on liquid chromatograph with spectrophotometric detector under the following conditions:

- Column nucleosil C18, 4.6×150 mm with a particle size of 5 microns;

- Mobile phase: methanol R - water R - acetic acid R - triethylamine R (55:44:1:0.1);

- The rate of mobile phase: $0.8 \mathrm{ml} /$ minutes;

- Column temperature: $25^{\circ} \mathrm{C}$.

\section{RESULTS AND DISCUSSION}

For an elaboration of the method, the chromatograms of the standard solution of amlodipine (Fig. 1), nifedipine (Fig. 2), and verapamil (Fig. 3), as well as the dependence of the intensity peaks on the retention time were obtained and analyzed.

In developing this technique, columns $\mathrm{C} 18$ were used, which has several advantages from a number of another column and provides high speed and high efficiency at a lower pressure system. This reduces the number of used mobile phase that according reduces the cost analysis [9-12].

The results of determining the degree of extraction of the substances under investigation are shown in Figs. 4-6.

The results of the study of API from calcium channel blockers (amlodipine, nifedipine, and verapamil) degree of extraction of various organic solvents, depending on the $\mathrm{pH}$ clearly indicate that the extraction of the drugs takes place already almost in neutral or basic solutions.

As can be seen from Fig. 4, amlodipine besylate is extracted with used organic solvents from both acidic and basic media. The area of maximum extraction for most solvents is observed at $\mathrm{pH}$ 7-8.

The obtained data indicate that the optimal solvents for the extraction of amlodipine besylate in the process of separating it from objects of biological samples are chloroform and methylene chloride. The amount of substance released by chloroform is $82.1 \%$ (at pH 7) and methylene chloride $71.5 \%$ (at $\mathrm{pH} 7$ ).

Considering that hexane does not extract amlodipine besylate from aqueous solutions ( $\mathrm{pH} 2$ ), it can be used to purify aqueous extract containing the preparation.

As can be seen from Fig. 5, nifedipine is extracted with used organic solvents from both acidic and basic media too. The area of maximum extraction for most solvents is observed at $\mathrm{pH}$ 5-6.

The obtained data summarize that the optimal solvents for the extraction of nifedipine in the process of its separation from objects of biological samples are also chloroform and methylene chloride. The amount of nifedipine isolated by chloroform and methylene chloride is $76.2 \%$ (at $\mathrm{pH} \mathrm{5}$ ) and $56.1 \%$ (at $\mathrm{pH}$ 5), respectively. In our further research, we will use chloroform. Hexane almost does not extract nifedipine from aqueous solutions that have a $\mathrm{pH}$ of 2; it can be used to clean aqueous extractors containing the preparation.

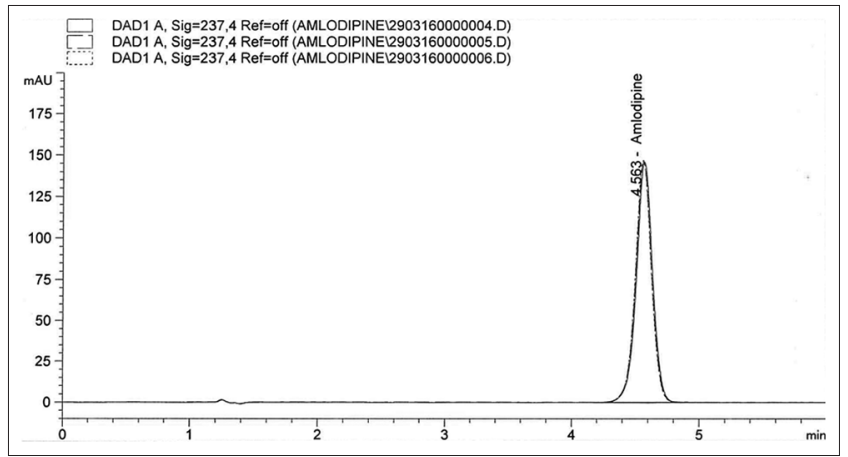

Fig. 1: Chromatogram of the standard solution of amlodipine besylate by high-performance liquid chromatography in the terms of the quantification of amlodipine

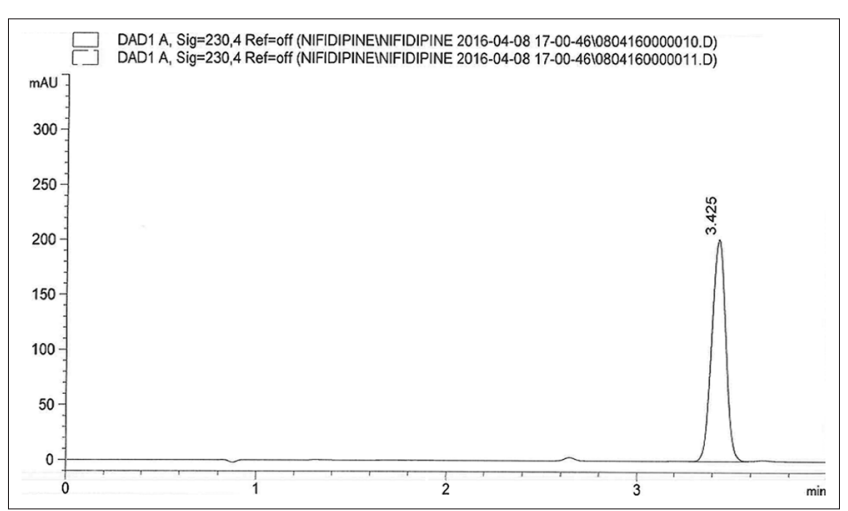

Fig. 2 Chromatogram of the standard solution of nifedipine by high-performance liquid chromatography in the terms of the quantification of nifedipine

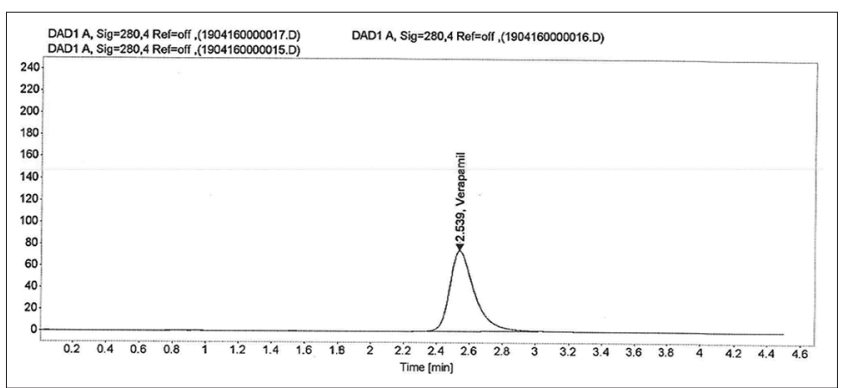

Fig. 3: Chromatogram of the standard solution of verapamil hydrochloride by high-performance liquid chromatography in the terms of the quantification of verapamil hydrochloride

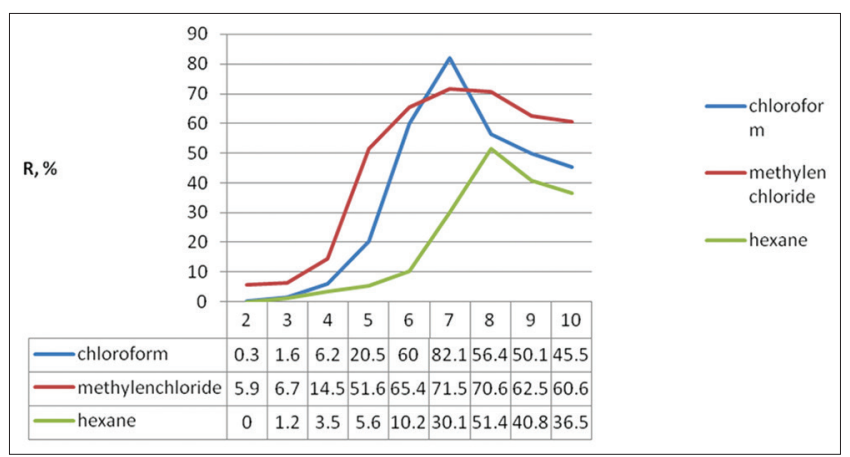

Fig. 4: The dependence of the degree of extraction of amlodipine besylate on $\mathrm{pH}$ solutions and nature of organic solvents 


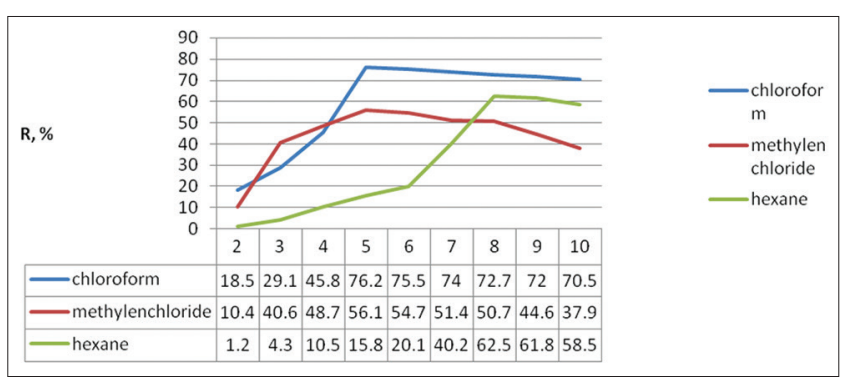

Fig. 5: The dependence of the degree of extraction of nifedipine on $\mathrm{pH}$ solutions and nature of organic solvents

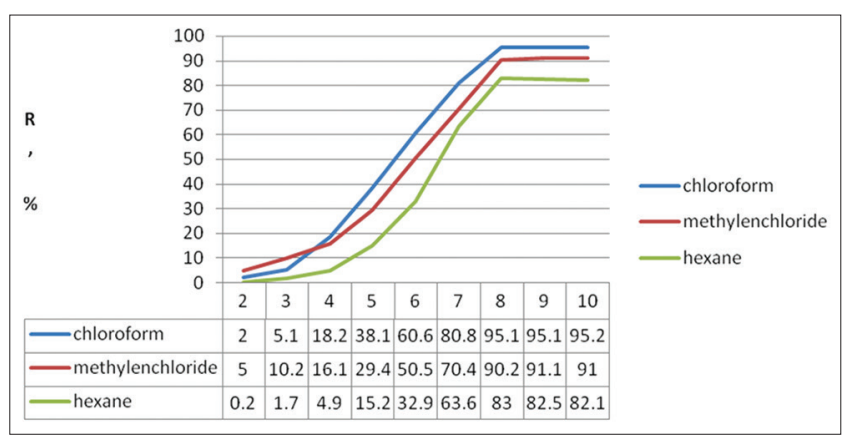

Fig. 6: The dependence of the degree of extraction of verapamil hydrochloride on $\mathrm{pH}$ solutions and nature of organic solvents

As can be seen from Fig. 6, verapamil hydrochloride is preferably extracted using the organic solvents from the basic medium. The area of maximum extraction for all solvents is observed at $\mathrm{pH}$ 8-10.

The obtained data indicate that the optimal solvents for the extraction of verapamil hydrochloride in the process of separating it from objects of biological samples are chloroform and methylene chloride. The amount of verapamil hydrochloride isolated by chloroform and methylene chloride is 95.1\% (at pH 8) and 91.1\% (at pH 9), respectively. Hexane almost does not extract verapamil hydrochloride from aqueous solutions that have a $\mathrm{pH}$ of 2 ; it can be used to purify aqueous extractors containing the preparation.

Results of the study are shown in Figs. 4-6 and indicate that API from calcium channel blockers (amlodipine, nifedipine, and verapamil) least extracted with hexane at $\mathrm{pH} 2$, so these conditions may be cleaned extracts from coextractives impurities.

At $\mathrm{pH}$ from 5.0 to 10.0 was marked the greatest numbers of methylenchloride and chloroform extraction of API from calcium channel blockers (amlodipine, nifedipine, and verapamil). The area of maximum extraction for most solvents (except nifedipine) begins at $\mathrm{pH} 7$ and continues until pH 9, followed by a decrease in the degree of extraction. Thus, the optimal extragent is chloroform, which is extracted at $\mathrm{pH} 7-82.1 \%$ of amlodipine, $\mathrm{pH} 5-76.2 \%$ of nifedipine, $\mathrm{pH} 8-95.1 \%$ verapamil hydrochloride.

\section{CONCLUSION}

1. The extraction of API from calcium channel blockers (amlodipine, nifedipine, and verapamil) by organic solvents from water solutions in dependence on $\mathrm{pH}$ solutions has been conducted.

2. As a result of studies, we have found that the optimal extragent is chloroform, which is extracted at $\mathrm{pH} 7-82.1 \%$ of amlodipine, $\mathrm{pH} 5-76.2 \%$ of nifedipine, $\mathrm{pH}$ 8-95.1\% verapamil hydrochloride.

3. We have found that API from calcium channel blockers (amlodipine, nifedipine, verapamil) least extracted with hexane at $\mathrm{pH} 2.0$, so these conditions may be cleaned extract from coextractives impurities.

\section{REFERENCES}

1. Clarke EJ. Isolation and Identification of Drugs in Pharmaceuticals, Body Fluids and Postmortem Material. London: Pharmaceutical Press, Electronic Version; 2005.

2. United States Pharmacopoeia (USP). Medicare Prescription Drug Benefit Model Guidelines Source Information. Available from: http:// www.nlm.nih.gov.

3. State Pharmacopoeia of Ukraine. In: State Enterprise Ukrainian Scientific Center Pharmacopoeia Quality Medicines. $2^{\text {nd }}$ ed., Vol. 2, 3. Kharkiv: State Enterprise Ukrainian Scientific Center of Quality Pharmacopoeia of Medicines; 2014. p. 724.

4. State Pharmacopoeia of Ukraine State Enterprise Scientific and Expert Centre Pharmacopoeia, Appendix 2. $1^{\text {st }}$ ed. Kharkiv: State Enterprise Ukrainian Scientific Center of Quality Pharmacopoeia of Medicines; 2008. p. 620

5. Logoyda L. Development and Validation of New methods of analysis for the determination of different natural and synthetic original active pharmaceutical ingredients in medicines. Duphat (Dubai International Pharmaceutical and Technologies Conference and Exhibition, UAE); 2015. p. 48

6. Liliya L, Dmutro K, Stanislav S. Development of methods for identification of calcium channel blockers in medicines. Int J Res Ayurveda Pharm 2016;7(2):88-91.

7. Logoyda L, Korobko D, Ivanusa I, Serhii K. Development of the methodology of the chromatographic determination of nifedipine in medicines. Asian J Pharm Clin Res 2017;10(3):149-52.

8. Kondratova Y, Adebayo T, Logoyda L, Korobko D, Berdey I, Kuchmerovska T. Development of the methodology of the chromatographic determination of amlodipine in medicines. Int J Res Ayurveda Pharm 2016;7(4):32-5.

9. Saifi M, Ali1 A, Saini M, Nasrullah N, Khan S, Abdin MZ. A rapid and efficient high-performance thin-layer chromatographic (HPTLC) method for simultaneous analysis of stevioside and rebaudioside-a in stevia rebaudiana. Int J Pharm Pharm Sci 2014;6(5):455-64.

10. Sharma T, Moitra SK, Si SC, Sankar DG. Development and validation of a HPLC method for the determination of valsartan and its degradation products in a pharmaceutical formulation. Int J Pharm Pharm Sci 2012;4(3):299-303.

11. Khaja P, Asgar A, Shanana B, Syed AH. Reverse phase-HPLC method for the analysis of tinidazole in the pharmaceutical dosage form and bulk drug. Int J Pharm Pharm Sci 2010;2:46-7.

12. Logoyda L. Validation of Chromatographic Methods of Analysis for the Determination of Active Pharmaceutical Ingredients in Different Medicines. Egypt: PharmaSchool Association for Pharmaceutical Development and Scientific Research; 2016. p. 34. 